Amy Marga

\title{
Karl Barth's Dialogue with Catholicism in Göttingen and Münster
}

\author{
Its Significance for His Doctrine of God
}

[Karl Barths Dialog mit dem Katholizismus in Göttingen und Münster. Die Bedeutung dieses Dialogs für seine Gotteslehre.]

Veröffentlicht auf Englisch.

Amy Marga untersucht die Belege für Karl Barths frühe Begegnung mit dem römischen Katholizismus und mit der analogia

AMY MARGA

Karl Barth's Dialogue with Catholicism in Göttingen and Münster

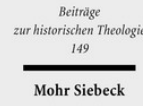

2010. VIII, 199 Seiten. BHTh 149

ISBN 978-3-16-151059-5

DOI 10.1628/978-3-16-151059-5

eBook PDF 104,00€

ISBN 978-3-16-150148-7

Leinen $104,00 €$ entis im Denken Erich Pryzwaras. Vor allem in seinen Vorlesungen zur Dogmatik in Göttingen und in seinen bisher unveröffentlichten Münsteraner Vorlesungen zum selben Thema zeigt sich Barths Interesse an der Gegenständlichkeit Gottes, die untrennbar mit dem trinitarischen Gott verbunden ist. Die Autorin arbeitet heraus, wie der Dialog mit dem Katholizismus Barth half, Klarheit über seine Doktrin der Offenbarung und des dreieinigen Gottes zu gewinnen.

Amy Marga Born 1972; 1995 BA in Christian Education from Concordia University, Saint Paul, MN; 1998 M.Div. from Princeton Theological Seminary, NJ; 2006 Ph.D. from Princeton Theological Seminary; Assistant Professor of Systematic Theology at Luther Seminary, Saint Paul, MN

Jetzt bestellen:

https://mohrsiebeck.com/buch/karl-barths-dialogue-with-catholicism-in-goettingen-and-muenster-9783161510595?

no_cache=1

order@mohrsiebeck.com

Telefon: $+49(0) 7071-923-17$

Telefax: +49 (0)7071-51104 